OPEN ACCESS

Edited by:

Conny Kopp-Scheinpflug, Ludwig Maximilian University of Munich, Germany

Reviewed by: lan D. Forsythe, University of Leicester, United Kingdom R. Michael Burger, Lehigh University, United States

${ }^{*}$ Correspondence: Jun Hee Kim kimih@uthscsa.edu

Received: 27 September 2021 Accepted: 07 January 2022 Published: 03 February 2022

Citation:

Wollet $\mathrm{M}$ and $\mathrm{Kim} \mathrm{JH}$ (2022) Brain-Derived Neurotrophic Factor Is Involved in Activity-Dependent Tonotopic Refinement of MNTB Neurons. Front. Neural Circuits 16:784396. doi: 10.3389/fncir.2022.784396

\section{Brain-Derived Neurotrophic Factor Is Involved in Activity-Dependent Tonotopic Refinement of MNTB Neurons}

\author{
Mackenna Wollet and Jun Hee Kim* \\ Department of Cellular and Integrative Physiology, UT Health San Antonio, San Antonio, TX, United States
}

In the mammalian brain, auditory brainstem nuclei are arranged topographically according to acoustic frequency responsiveness. During postnatal development, the axon initial segment (AIS) of principal neurons undergoes structural refinement depending on location along the tonotopic axis within the medial nucleus of the trapezoid body (MNTB). However, the molecular mechanisms underlying the structural refinement of the AIS along the tonotopic axis in the auditory brainstem have not been explored. We tested the hypothesis that brain-derived neurotrophic factor (BDNF) is a molecular mediator of the structural development of the MNTB in an activitydependent manner. Using BDNF heterozygous mutant $\left(B D N F^{+/-}\right)$mice, we examined the impact of global BDNF reduction on structural and functional development of MNTB neurons by assessing AIS structure and associated intrinsic neuronal properties. BDNF reduction inhibits the structural and functional differentiation of principal neurons along the tonotopic axis in the MNTB. Augmented sound input during the critical period of development has been shown to enhance the structural refinement of the AIS of MNTB neurons. However, in $B D N F^{+/-}$mice, MNTB neurons did not show this activitydependent structural modification of the AIS following repeated sound stimulation. In addition, $B D N F^{+/-}$mice lacked a defined isofrequency band of neuronal activity following exposure to $16 \mathrm{kHz}$ sound, suggesting degradation of tonotopy. Taken together, structural development and functional refinement of auditory brainstem neurons require physiological levels of BDNF to establish proper tonotopic gradients.

Keywords: BDNF, auditory brainstem, MNTB, tonotopy, axon initial segment

\section{INTRODUCTION}

Along the auditory processing pathway, the topographic organization of neurons is important for determining where sound frequencies are processed within each auditory nucleus. In the MNTB, one of the key sound localization nuclei in the auditory brainstem, neurons are arranged with graded frequency-responsiveness (from high- to low-frequency) along the medio-lateral axis, respectively. Physiological factors including ion channel expression and cell morphology 
(e.g., soma size) are graded along the tonotopic axis in brainstem nuclei (Weatherstone et al., 2017; Akter et al., 2018). For example, voltage-gated potassium channel $\left(\mathrm{K}_{\mathrm{V}} 3\right)$ is highly expressed in high-frequency responding neurons, and expression decreases moving toward low-frequency responding neurons in a graded fashion in the mouse and avian brainstem (Li et al., 2001; Parameshwaran et al., 2001; von Hehn et al., 2004; Leao et al., 2006). In contrast to $K_{V} 3$ channels, $K_{V} 1$ channels have the opposite expression pattern within the MNTB with the highest $\mathrm{K}_{\mathrm{V}} 1$ density laterally (Leao et al., 2006). In terms of cell morphology, the soma size of MNTB neurons is different along the tonotopic axis, where lateral neurons are larger than medial neurons (Weatherstone et al., 2017). In addition, the length and location of the AIS, a key axonal domain responsible for action potential (AP) initiation and neuronal excitability, is also dependent on cell location along the tonotopic axis in the chick and mouse (Kuba et al., 2006, 2014; Kim et al., 2019). Tonotopic refinement of the AIS is impaired in deaf animals- either congenitally or via cochlear removal (Kuba et al., 2010; Kim et al., 2019). Oppositely, AIS tonotopic differentiation is enhanced following increased neural activity driven by acoustic enrichment during the critical development period in mice (Kim et al., 2019). The structural refinement of the AIS is dependent on tonotopic location and requires sound-evoked activity in the auditory brainstem. The AIS determines neuronal excitability and modulates neuronal output, thus can control auditory processing along the ascending auditory pathway (Kuba et al., 2006; Grubb and Burrone, 2010). However, the molecular mechanisms driving establishment of the tonotopic gradient of the AIS in the MNTB are unknown.

Previous work in cultured hippocampal neurons showed BDNF signaling regulates AIS location and affects neuronal excitability (Guo et al., 2017). Here, we investigated whether BDNF, an essential molecule for activity-dependent plasticity, is a molecular mediator for establishing tonotopic gradients of the AIS and associated neuronal properties in the auditory brainstem. BDNF expression begins in the inner ear at postnatal day 4 (P4) and the expression pattern follows the ascending pathway during development (Hafidi, 1999; Wiechers et al., 1999). By P14, BDNF mRNA expression is arranged tonotopically within the cochlea where expression is highest in the apical and medial turns, opposite of the NT3 mRNA expression gradient (Schimmang et al., 2003). Acoustic enrichment increases BDNF transcript levels and protein levels in rodent brainstem due to increased neuronal activity (Wang et al., 2011; Matt et al., 2018). Using anti-BDNF antibodies to neutralize BDNF signaling, activity-dependent plasticity of tonotopy following pure tone sound stimulation was prevented in the rat auditory cortex (Anomal et al., 2013). We studied the effects of globally reduced BDNF levels on structural and intrinsic properties of MNTB neurons along the tonotopic axis in $B D N F^{+/-}$mice. Given the role of BDNF in sound-evoked activity, tonotopic plasticity, and structural differentiation, we found that BDNF is one of the molecular mediators responsible for establishing structural tonotopic gradients and related physiological properties of auditory brainstem neurons during postnatal development.

\section{MATERIALS AND METHODS}

\section{Animals}

Both sexes of wild-type (WT) mice and $B D N F^{+/-}$mice with a C57BL/6J background were used under the guidelines approved by the UT Health San Antonio Institutional Animal Care and Use Committee. BDNF heterozygous mice (B6.129S4-Bdnftm1Jae/J) were obtained from Jackson Labs in heterozygous breeding pairs. All experiments were done between postnatal days 9 and 11 (P9-P11; Figure 3) and P18-P23 (Figures 1, 2, 4, 5) during the animals' light cycle. Animals were housed in a 12-h light/dark cycle.

\section{Sound Stimulation}

Mice were exposed to random noise centered at $16 \mathrm{kHz}$ frequency at $80 \mathrm{~dB}$ during their light cycle for $3 \mathrm{~h}$ per day from P13 to P19 (Figure 4). Sixteen $\mathrm{kHz}$ pure tone exposure at $80 \mathrm{~dB}$ occurred during the light cycle for $90 \mathrm{~min}$ preceded by $60 \mathrm{~min}$ of silence in the sound attenuation chamber (Figure 5; Med Associates, Albans, VT) and the stimuli were generated by Tucker Davis Technologies equipment and software.

\section{Slice Preparation}

Mice were anesthetized with isoflurane then rapidly decapitated. The brains were then quickly removed and immersed in ice-cold low-calcium artificial cerebrospinal fluid (aCSF) containing (in $\mathrm{mM}$ ): $125 \mathrm{NaCl}, 2.5 \mathrm{KCl}, 3 \mathrm{MgCl}_{2}, 0.1 \mathrm{CaCl}_{2}, 25$ glucose, $25 \mathrm{NaHCO}_{3}, 1.25 \mathrm{NaH}_{2} \mathrm{PO}_{4}, \mathrm{pH} 7.4$ bubbled with carbogen (95\% $\mathrm{O}_{2}, 5 \% \mathrm{CO}_{2}$; osmolarity 310-320 mOsm. Transverse $200 \mu \mathrm{m}$-thick brainstem slices containing the MNTB were collected using a Vibratome (VT1200S, Leica, Germany). Slices were then prepared further for either electrophysiology or immunohistochemistry experiments.

\section{Immunohistochemistry}

Brain slices were fixed with $4 \%$ paraformaldehyde (PFA) for 10 min then washed with PBS three times. Free-floating slices were blocked in $4 \%$ goat serum and $0.3 \%(\mathrm{w} / \mathrm{v})$ Triton $\mathrm{X}-100$, $0.1 \%$ Tween 20 in PBS for $1 \mathrm{~h}$ and then were incubated with primary antibody overnight at $4^{\circ} \mathrm{C}$. Primary antibodies used: Anti-Ankyrin G (Mouse IgG1, NeuroMab, 1:200), Anti-MAP2 (Rabbit or Mouse IgG1, Millipore, 1:500), Anti- $\beta 4$-spectrin (Rabbit; Bhat lab, UTHSCSA, 1:500), Anti-c-Fos (Rabbit, Synaptic Systems, 1:500). Slices were washed with PBS three times then incubated with corresponding secondary antibodies for $2 \mathrm{~h}$ at room temperature. Secondary antibodies (Invitrogen): Alexa Fluor 555 goat anti-GP, Alexa Fluor 488 goat anti-rabbit, and Alexa Fluor 647 goat anti-mouse IgG1 all at 1:500 dilution. Analysis of Z-stack confocal images was performed in Fiji. Medial neurons are in the most medial $30 \%$ of the MNTB, and lateral neurons are located in the most lateral $30 \%$ of the MNTB. Identification of neuronal AIS utilized either AnkG or $\beta 4$-spectrin on $\mathrm{MAP}^{+}$cells. A segmented line tool in Fiji was used to measure length and distance from the soma. AIS length 
A

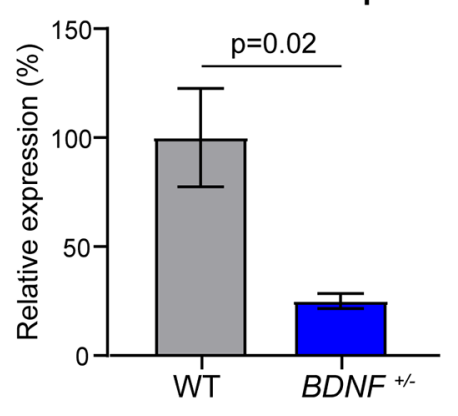

BDNF Protein Levels

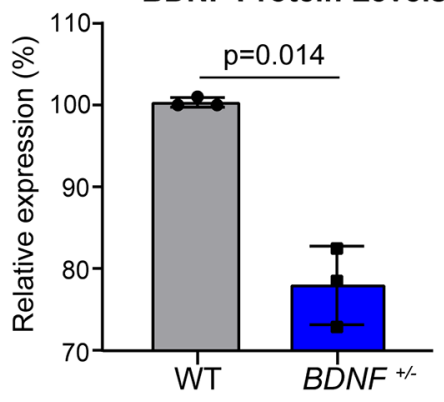

B

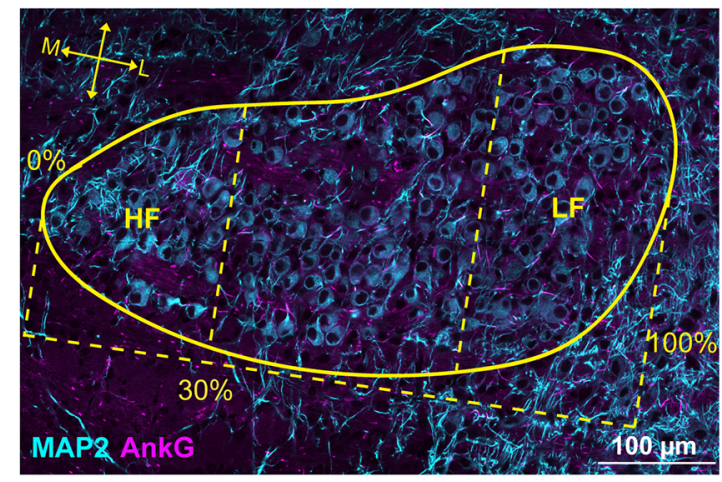

Medial

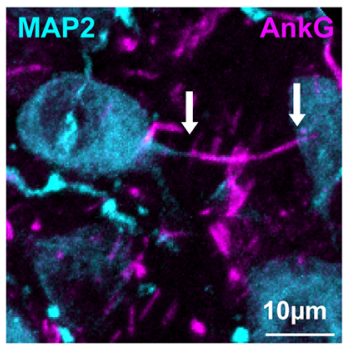

Lateral

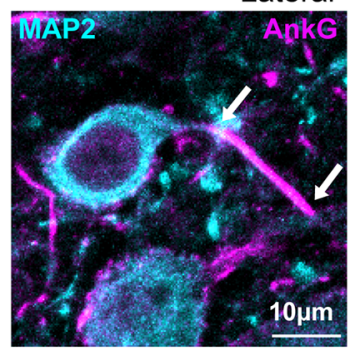

C

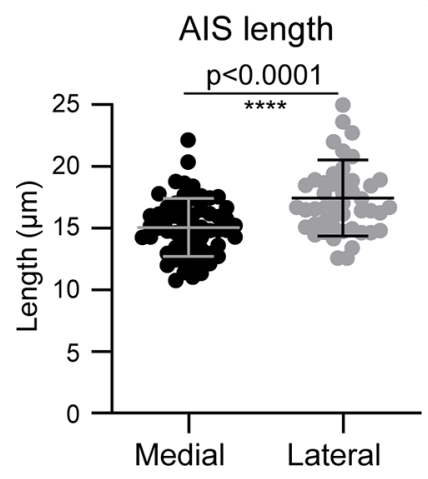

WT

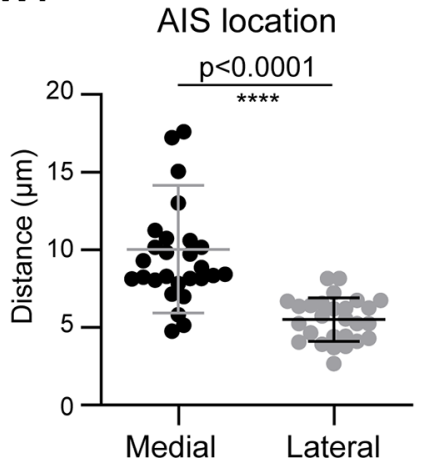

D

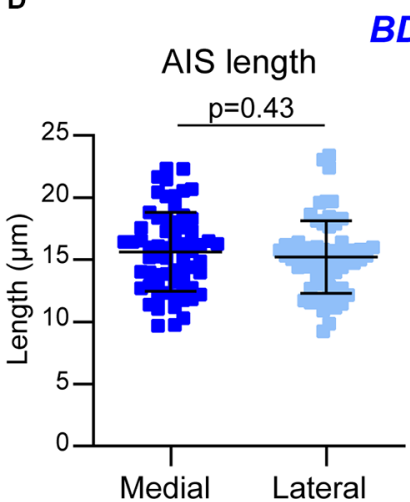

$B D N F^{+/-}$

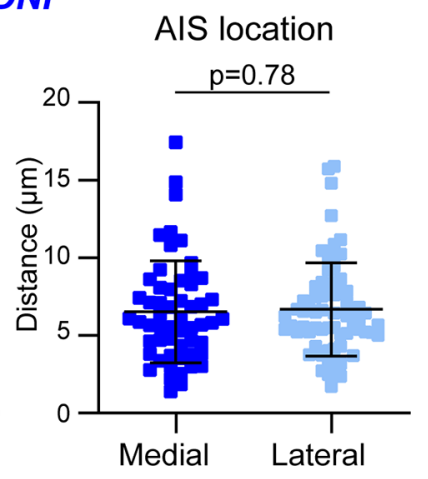

FIGURE 1 | The tonotopic arrangement of the AIS in MNTB neurons is abolished in BDNF ${ }^{+/-}$mice. (A) BDNF mRNA expression (top) and BDNF protein level (bottom) in the MNTB from WT and BDNF ${ }^{+/-}$mice using qPCR and Western Blot, respectively. BDNF mRNA expression and protein level from BDNF ${ }^{+/-}$mice were normalized by those from WT (indicated by Relative expression, \%). (B) The MNTB (at P20, the yellow line indicates border) was immunostained with MAP2 (cyan) and AnkG (magenta). HF indicates the high-frequency responding region, 30\% of the medial (M) MNTB, and LF indicates the low-frequency responding region, 30\% of the lateral (L) MNTB. (Bottom) Magnified images of medial and lateral MNTB neurons of BDNF ${ }^{+/-}$mice. Arrows indicate the proximal and distal ends of AIS. (C) Summary of length $(\mu \mathrm{m})$ and location (distance from the soma) of the AIS in WT MNTB neurons. (D) AIS length and distance from soma from BDNF+/- medial and lateral neurons. Each point represents individual cells from three WT mice and four BDNF ${ }^{+/-}$mice. All error bars represent mean \pm SD. ${ }^{\star \star \star \star}$ indicates $p<0.0001$.

was measured from the proximal end of $\mathrm{AnkG}^{+}$(or $\beta 4$-spectrin ${ }^{+}$) signal to the most distal end, and AIS location was measured from the proximal end of $\mathrm{AnkG}^{+}$(or $\beta 4$-spectrin ${ }^{+}$) signal to edge of cell soma. For c-Fos analysis, the double staining against MAP2 and c-Fos were performed from $\mathrm{WT}$ and $B D N F^{+/-}$mice. MAP2- and c-Fos-positive cells (c-Fos ${ }^{+}$neurons) were counted using the cell counter plugin of Fiji software. Only the cells with $\mathrm{c}-\mathrm{Fos}^{+}$nuclei were counted and the constant threshold level of fluorescence intensity was used in each slice. The percentage of c-Fos ${ }^{+}$cells was calculated by dividing the number of $\mathrm{c}-\mathrm{Fos}^{+}$
$\mathrm{MAP}^{+} \mathrm{MNTB}$ neurons by the total number of $\mathrm{MAP}^{+} \mathrm{MNTB}^{+}$ neurons in each slice. Details were described in Kim et al. (2019).

\section{Electrophysiology}

After vibratome sectioning, slices were incubated in a chamber containing normal aCSF bubbled with carbogen at $35^{\circ} \mathrm{C}$ for $30 \mathrm{~min}$ and then kept at room temperature. The normal aCSF was the same as the low-calcium aCSF, except $3 \mathrm{mM} \mathrm{MgCl}_{2}$ and $0.1 \mathrm{mM} \mathrm{CaCl} 2$ were increased to $1 \mathrm{mM} \mathrm{MgCl}_{2}$ and $2 \mathrm{mM} \mathrm{CaCl}_{2}$. Whole-cell patch-clamp recording was carried 


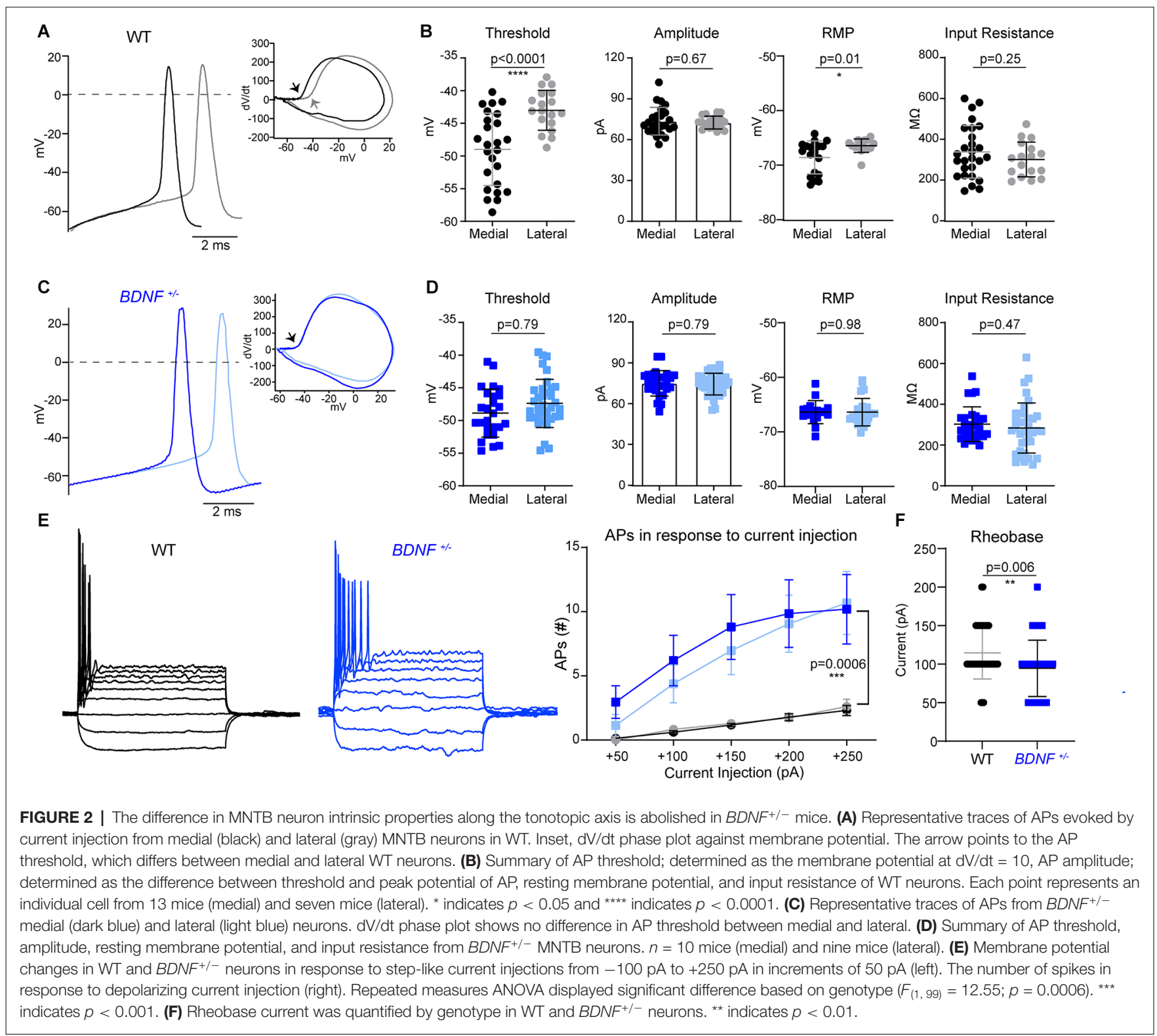

out on postsynaptic principal neurons in the MNTB at room temperature $\left(\sim 24^{\circ} \mathrm{C}\right)$. Action potentials (APs) were recorded in normal aCSF using the current-clamp mode of the EPC-10 (HEKA Electronik, Lambrecht/Pfalz, Germany). The pipettes were filled with an internal solution containing (in $\mathrm{mM}$ ) $125 \mathrm{~K}$ gluconate, $20 \mathrm{KCl}, 5 \mathrm{Na}_{2}$-phosphocreatine, $10 \mathrm{HEPES}, 4 \mathrm{Mg}$ ATP, 0.2 EGTA, and $0.3 \mathrm{GTP}, \mathrm{pH}$ adjusted to 7.3 with $\mathrm{KOH}$. The holding potential was $-65 \mathrm{mV}$ in the voltage-clamp mode. Current-clamp protocols were $200 \mathrm{~ms}$ in duration with current steps from -100 to $250 \mathrm{pA}$ ( $50 \mathrm{pA}$ increments). Patch electrodes had resistances of 4-5 M $\Omega$. Series resistance was $<15 \mathrm{M} \Omega$ without compensation. The threshold of AP was determined by the point where $\mathrm{dV} / \mathrm{dt}$ exceeds $10 \mathrm{~V} / \mathrm{s}$ and the amplitude of AP from the threshold to the AP peak in the plot of $\mathrm{dV} / \mathrm{dt}$ and voltage, which were taken from the first AP evoked in depolarizing current injection protocol. Data were analyzed and displayed with Igor Pro (Wavemetrics, Lake Oswego, OR, United States).

\section{Western Blot}

Whole tissue lysate of WT and $B D N F^{+/-}$brainstems (at P21) were extracted with RIPA buffer. Equal protein amounts were loaded onto a $4-15 \%$ Tris/Glycine precast gel (Bio-Rad) and transferred to a nitrocellulose membrane. Membranes were blotted with anti-BDNF (Rb, 1:200, Abcam) and anti- $\beta$-actin (Mouse, 1:1,000; Abcam), which was used for normalization. Fluorescent secondary antibodies used: Mouse-800CW (1:7,500, LI-COR) and Rabbit-680RD (1:7,500, LI-COR). Membranes were imaged on Odyssey CLx (LI-COR), and images analyzed using Fiji software. 
A
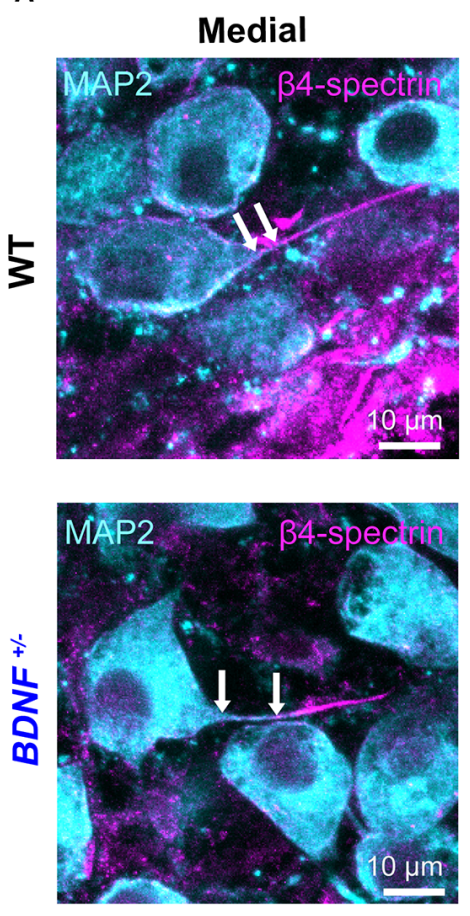

C

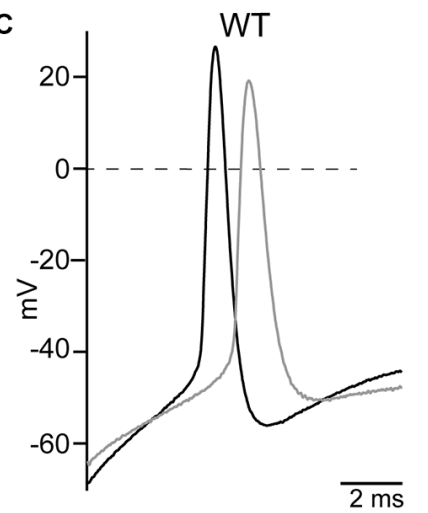

E

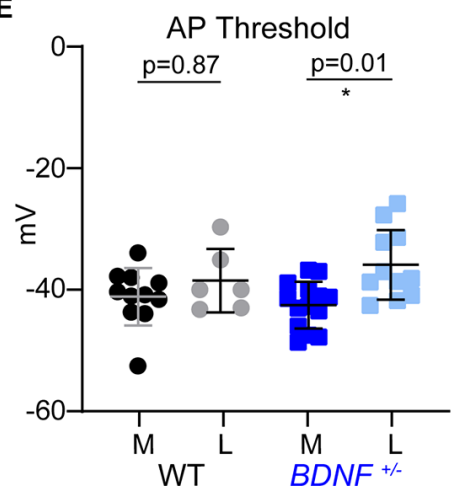

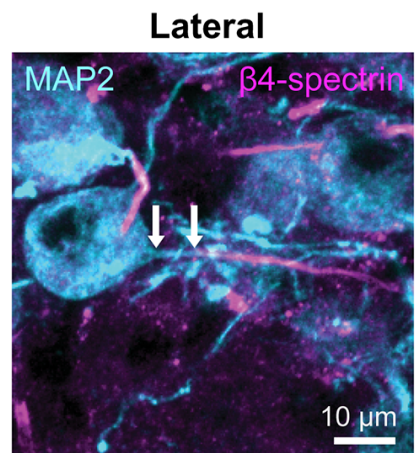

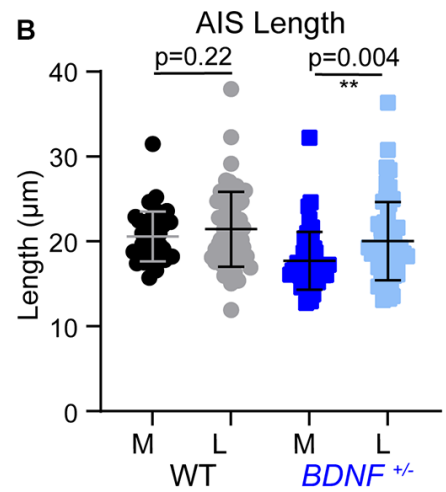

AIS Location

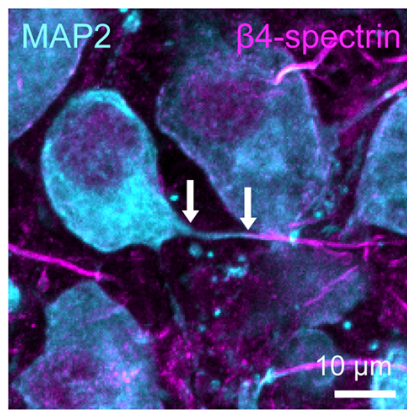

$B D N F^{+/-}$

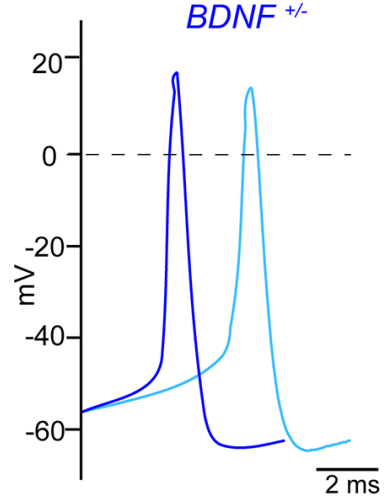

AP Amplitude

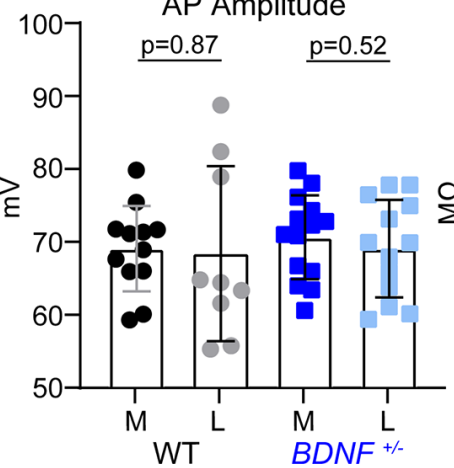

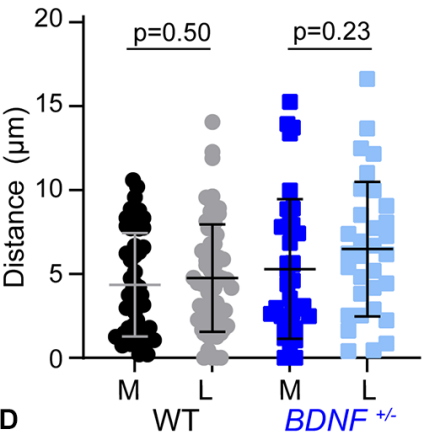
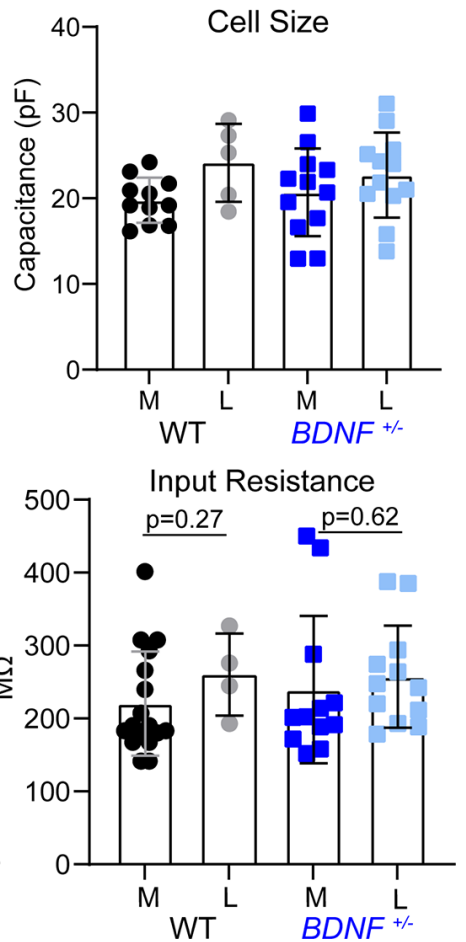

FIGURE 3 | AIS structures and intrinsic properties of MNTB neurons at pre-hearing age. (A) MNTB neurons (MAP2, cyan) and corresponding AIS ( $\beta 4$-spectrin, magenta) of WT and $\mathrm{BDNF}^{+/-}$mice (at P9). Scale bar represents $10 \mu \mathrm{m}$. Arrows point to the edge of the soma and proximal end of the AIS, indicating the distance of the AIS. (B) Quantification of AIS location and length according to genotype and tonotopic location. Each point represents an individual cell from three mice/group. ${ }^{* *}$ indicates $p<0.01$. (C) Representative AP traces of medial and lateral neurons from WT and BDNF ${ }^{+/-}$mice. (D) Individual cell size was quantified by capacitance (pF) measurements during whole-cell recordings. Each point represents an individual cell. (E) Summary of AP threshold, amplitude, and input resistance by genotype and tonotopic location from five WT mice and four $B D N F^{+/-}$mice. * indicates $p<0.05$. 
A

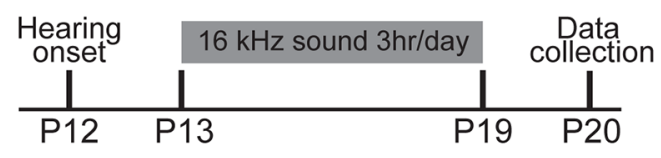

B

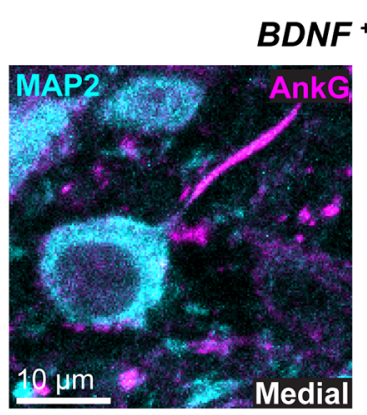

D $B D N F^{+\kappa}+$ Sound

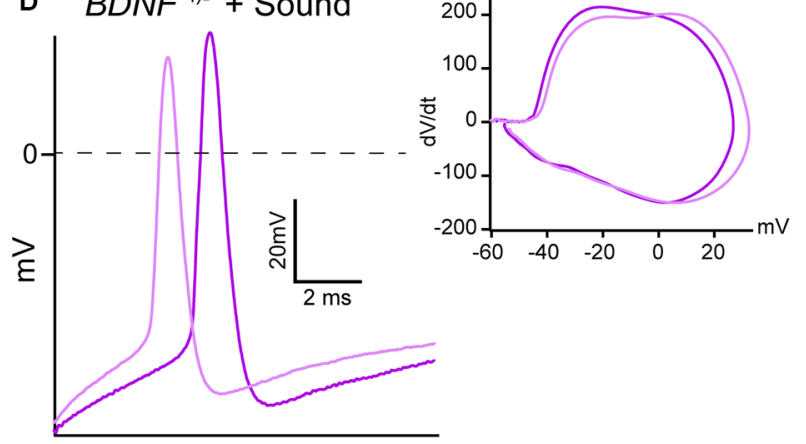

Pro-BDNF

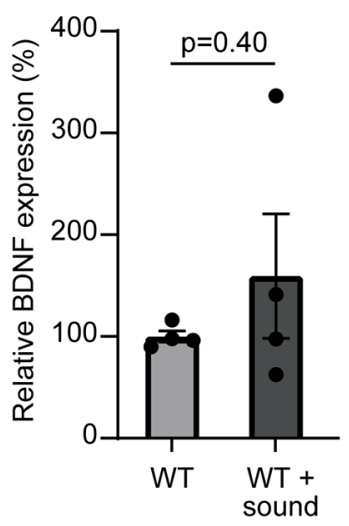

C AIS Length

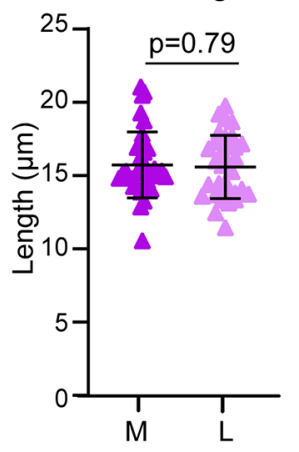

E

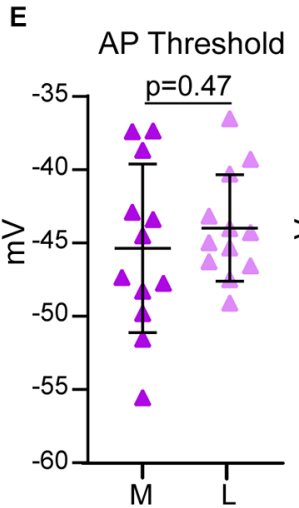

Mature BDNF

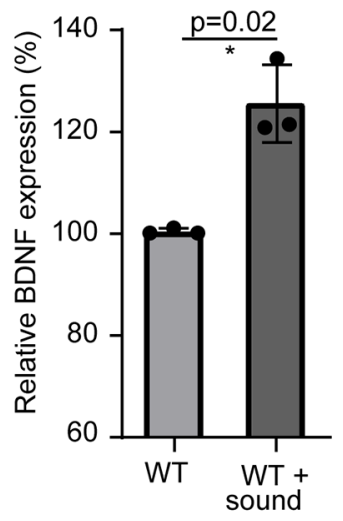

AIS Location

Capacitance
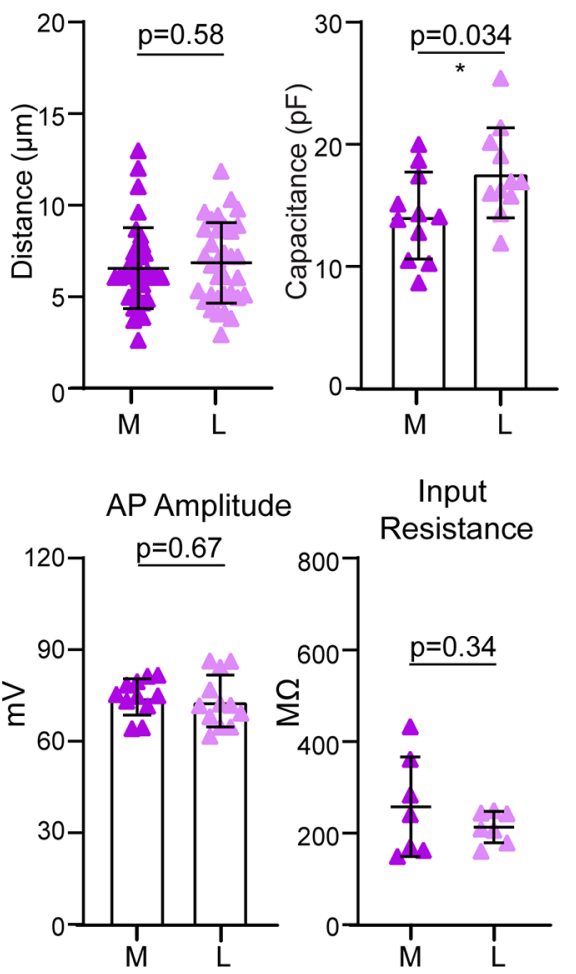

Input Resistance

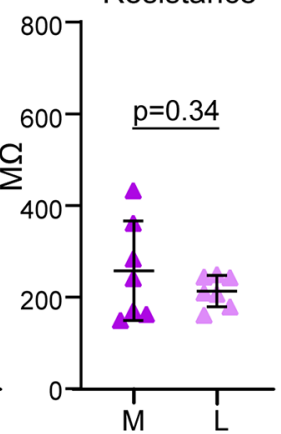

FIGURE 4 | BDNF is necessary for the activity-dependent plasticity of MNTB neurons. (A) Sound stimulation paradigm schematic; 16 kHz sound for 3 h/day from P13 to P19 followed by data collection and mature and pro-BDNF protein levels in WT and WT + sound. * indicates $p<0.05$. (B) MNTB neurons of BDNF+/- mice following sound stimulation were immunostained with anti-MAP2 (cyan) and anti-AnkG (magenta). (C) AIS length and location, and cell size were quantified by condition and tonotopic location. Each point represents individual cells from four mice for BDNF $F^{+/-}$and three mice for $B D N F^{+/-}+$sound. (D) Representative AP traces from $B D N F^{+/-}$medial (dark purple) and lateral (light purple) neurons after sound stimulation. Inset, dV/dt phase plot against membrane potential. (E) Summary of AP threshold, amplitude, and input resistance were quantified for each condition and tonotopic location. Each point represents an individual cell.

\section{Quantitative Polymerase Chain Reaction (qPCR)}

RNA isolation and reverse transcription reaction were performed as previously described in Kim et al. (2019). RNA extraction was done from p9 whole brain tissue of WT and $B D N F^{+/-}$ mice using RNAqueous kit with no alterations to procedure (AM1931, Thermofisher). qPCR was executed using 7900HT Fast Real-Time PCR system (Applied Biosystems), data were analyzed using SDS v2.4 (Applied Biosystems). GAPDH was used as a reference housekeeping gene. Delta $(\Delta) \mathrm{CT}\left(\right.$ Mean $_{\mathrm{Gene}}{ }^{-}$ Mean $\left._{\mathrm{GAPDH}}\right)$ was utilized to calculate $\Delta \Delta \mathrm{CT}\left(\Delta \mathrm{CT}_{\mathrm{Pos}}-\Delta \mathrm{CT}_{\mathrm{Neg}}\right)$, and data was normalized to WT (100\%). Mouse primers used: BDNF Forward: 5'-TCGTTCCTTTCGAGTTAGCC, BDNF Reverse: 5'-TTGGTAAACGGCACAAAAC, GAPDH Forward: 5'AGTATGACTCCACTCACGGCAA, and GAPDH Reverse: 5'-TCTCGCTCCTGGAAGATGGT. 


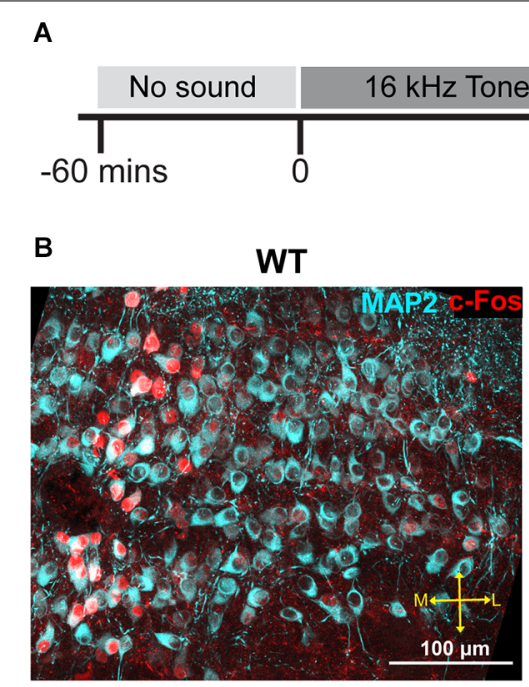

D
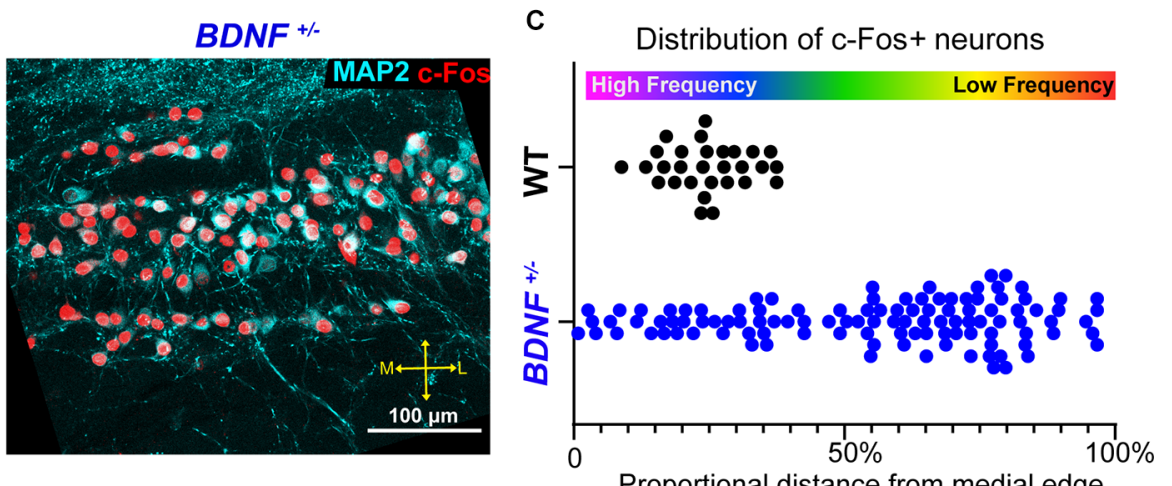

E

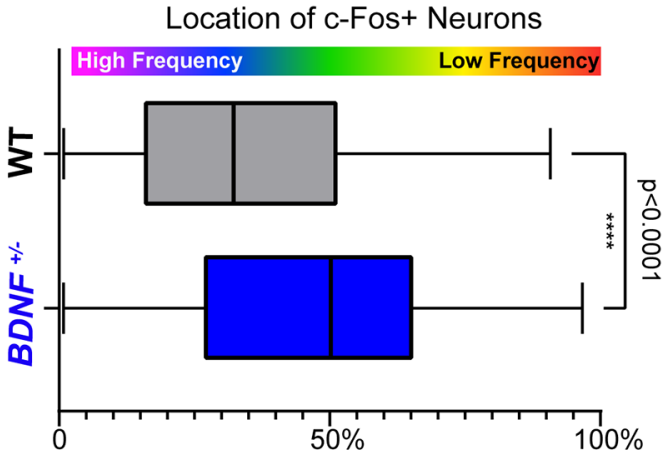

Proportional distance from medial edge

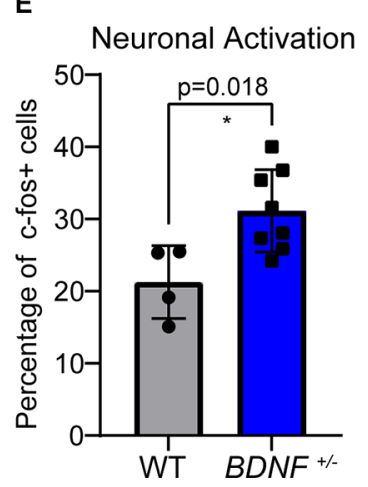

FIGURE 5 | High frequency sound responding neurons is not tonotopically organized in BDNF+/- mice. (A) Tone exposure paradigm schematic. P21 mice were exposed to a pure $16 \mathrm{kHz}$ tone for 90 min preceded by 60 min of silence in a sound-attenuated chamber. (B) Representative image of the MNTB immunostained with MAP2 (cyan) and c-Fos (red). Scale bars represent $100 \mu \mathrm{m}$. (C) Quantification of the representative image in (B) displayed as proportional location of each $\mathrm{C}^{-F_{0 S}}{ }^{+}$neuron from the medial edge of MNTB (see the MNTB border and proportional location in Figure 1B). Each point represents one cell. Activated MNTB neurons in BDNF+/- are more laterally located (median: $24.29 \%$ in $B D N F^{+/}$and $61.12 \%$ in WT; $p<0.0001$, Mann-Whitney $U$ test). (D) Distribution analysis of c-Fos ${ }^{+}$ neurons displayed as the proportional distance from the medial edge of MNTB where $0 \%$ is the medial edge of the MNTB and $100 \%$ is the most lateral edge of the MNTB. Activated MNTB neurons in $\mathrm{BDNF}^{+/-}$are more laterally located $(p<0.0001$, Mann-Whitney $U$ test) and widespread compared to WT ( $p<0.0001$, Kolmogorov-Smirnov test). ${ }^{* * *}$ indicates $p<0.0001$. (E) Quantification of c-Fos ${ }^{+}$neurons divided by total MNTB neurons between genotypes. BDNF ${ }^{+/-}$mice $(n=5)$ have larger proportion of c-Fos ${ }^{+}$MNTB neurons compared to WT $(n=3)$ mice $(p=0.018$, Wel.ch's $t$-test). * indicates $p<0.05$.

\section{Statistics}

All statistical analyses were performed in GraphPad Prism version 9.2.0 for Windows (GraphPad Software, San Diego, CA, United States). The normality of datasets was analyzed using the Kolmogorov-Smirnov test. Parametric or non-parametric tests were carried out accordingly. To compare the two groups, an unpaired $t$-test with Welch's correction (parametric) or Mann-Whitney $U$ test (nonparametric) was carried out. To compare three or more groups, one-way ANOVA with Turkey's multiple comparison test was used. Values in results are represented as mean $\pm \mathrm{SD}$. Error bars in figures are $\pm \mathrm{SD}$. In Figure 5, KolmogorovSmirnov tests are used to evaluate the distribution of $\mathrm{c}$-Fos ${ }^{+}$ cells. Figure 5 contains a box and whisker plot with the median as the center to display neuron distribution within the MNTB.

\section{RESULTS}

\section{Global Reduction of BDNF Impairs Structural Differentiation of the AIS Along the Tonotopic Axis in the MNTB}

The AIS of MNTB neurons is differentiated by structure and function along the tonotopic axis during postnatal development (Kim et al., 2019). To determine whether BDNF mediates the structural refinement of the AIS along the tonotopic axis, we examined the effects of globally reduced BDNF on AIS 
length and location along the medial-lateral axis in the MNTB using $B D N F^{+/-}$mice. Analysis of BDNF mRNA and protein using $\mathrm{QPCR}$ and Western Blot respectively showed a significant reduction of $B D N F$ mRNA expression and BDNF protein level in $B D N F^{+/-}$mice compared to WT (mRNA: $\sim 75 \%$ reduction in $B D F^{+/-}, p=0.026$, Welch's $t$-test, $n=2$ and 3; protein: $\sim 22 \%$ reduction in $B D N F^{+-}, p=0.014$, Welch's $t$-test, $n=3$ /group; Figure 1A). In WT and $B D N F^{+/-}$mice (at $\mathrm{P} 20 \pm 2$ days), we quantified the AIS length and location, measured by the distance from principal neuron soma, as described in Kim et al. (2019). The MNTB was proportionally defined by the percent of the total distance from medial to lateral edges of the MNTB, where medial neurons are within $30 \%$ of the medial MNTB border and lateral neurons are within $30 \%$ of the lateral MNTB border (Figure 1B). Using MAP2 and AnkG immunostaining, we examined the effect of reduced BDNF on AIS structural properties of MNTB neurons along the tonotopic axis in $B D N F^{+/-}$mice (Figure 1C). In WT mice, the AIS length and location of medial MNTB neurons were significantly different from lateral MNTB neurons. In WT mice, the AIS length was $15.05 \pm 2.35 \mu \mathrm{m}(n=59$ cells $)$ for medial neurons and $17.43 \pm 3.09 \mu \mathrm{m}(n=48$ cells $)$ for lateral neurons ( $p<0.0001$; Welch's 2 -tailed $t$-test). The AIS distance from the soma was $10.03 \pm 4.10 \mu \mathrm{m}$ (medial) and $5.51 \pm 1.40 \mu \mathrm{m}$ (lateral, $p<0.0001$, Welch's 2-tailed $t$-test; $n=27$ and 28 cells respectively; Figure 1D). Consistent with our previous work (Kim et al., 2019), AIS length was significantly shorter and more distal from the soma in medial MNTB neurons compared to lateral MNTB neurons. In $B D N F^{+/-}$mice, MNTB neurons did not show this structural differentiation in the AIS length or distance along the tonotopic axis. AIS length was $15.64 \pm 3.19 \mu \mathrm{m}$ in medial neurons and $15.21 \pm 2.92 \mu \mathrm{m}$ in lateral neurons ( $p=0.43$, Student's $t$-test, $n=66$ and 64 cells respectively). AIS distance from soma was $6.53 \pm 3.29 \mu \mathrm{m}$ in medial neurons and $6.68 \pm 2.99 \mu \mathrm{m}$ in lateral neurons $(p=0.78$, Student's $t$-test, $n=56$ and 68 cells respectively; Figure 1E). Reduced global BDNF disrupts the tonotopic refinement of AIS properties in the MNTB, indicating that BDNF is associated with the structural development of MNTB neurons. In addition to AIS structural properties, the soma size of MNTB neurons is dependent on location; lateral MNTB neurons are larger than medial neurons (Weatherstone et al., 2017). In the current study, membrane capacitance measurements using whole-cell patch-clamp recordings showed the tonotopic gradient in WT neurons. WT medial neurons had membrane capacitance of $17.02 \pm 4.25 \mathrm{pF}(n=25)$, whereas lateral neurons had $20.11 \pm 4.65 \mathrm{pF}(n=32$ neurons, $p=0.01$, Student's $t$-test; Table 1). Similarly, $B D N F^{+/-}$mice maintained the tonotopic differentiation of membrane capacitance: medial neurons had a smaller capacitance $(13.72 \pm 3.20 \mathrm{pF}, n=27)$ than lateral neurons $(17.18 \pm 3.16 \mathrm{pF}, n=37, p<0.0001$, Student's $t$-test; Table 1). Notably, regardless of neuron location, MNTB neurons were significantly smaller in $B D N F^{+/-}$mice compared to WT. Taken together, the reduction of BDNF disrupts the tonotopic differentiation of AIS length and location in the MNTB. The result indicates that globally reduced levels of BDNF impair the structural development of MNTB principal neurons along the tonotopic axis.

\section{Tonotopic Organization of MNTB Neuron Intrinsic Properties Is Abolished in BDNF $^{+/-}$Mouse}

Next, we investigated how structural alterations of the AIS, caused by BDNF reduction, impact the intrinsic properties and firing pattern of MNTB neurons in $B D N F^{+/-}$mice. APs were recorded from medial and lateral MNTB neurons in response to current injections (from $-100 \mathrm{pA}$ to $250 \mathrm{pA}, \Delta=50 \mathrm{pA}$ ). Phasic plotting the $\mathrm{dV} / \mathrm{dt}$ of APs from MNTB neurons, evoked by a depolarizing current injection, was analyzed (Figure 2A). In WT mice (at P20), medial neurons had a lower AP threshold and resting potential (more hyperpolarized) compared with lateral neurons, indicating there was a difference in intrinsic properties of MNTB neurons along the tonotopic axis (Threshold, medial: $-48.98 \pm 5.53 \mathrm{mV}$ and lateral: $-41.86 \pm 3.06 \mathrm{mV}, p<0.0001$, Welch's test; RMP, medial: $-68.58 \pm 3.03 \mathrm{mV}$ and lateral: $-66.42 \pm 1.22 \mathrm{mV}, p=0.01$, Welch's test). However, there was no difference in AP amplitude, half-width, or input resistance between medial and lateral WT neurons (Figure 2B, Table 1). In $B D N F^{+/-}$mice, there was no difference in AP threshold or resting membrane potential of MNTB neurons along the tonotopic axis (Figures 2C,D). AP threshold was $-48.87 \pm$ $3.68 \mathrm{mV}(n=26)$ in medial neurons and $-47.38 \pm 3.68 \mathrm{mV}$ $(n=36)$ in lateral neurons ( $p=0.12$, Student's $t$-test). RMP was $-66.38 \pm 2.12 \mathrm{mV}(n=17)$ in medial neurons and -66.40 $\pm 2.52 \mathrm{mV}(n=24)$ in lateral neurons $(p=0.98$, Student's $t$ test). There was no difference in AP amplitude, half-width, or input resistance between medial and lateral neurons in $\mathrm{BDNF}^{+/-}$ mice (Figure 2D, Table 1). Thus, global BDNF reduction affects tonotopic differentiation in the AIS and intrinsic properties of MNTB neurons during postnatal development.

Regardless of their location along the tonotopic axis, MNTB neurons from $B D N F^{+/-}$mice showed an increased number of AP spikes evoked by depolarizing current injections $(50 \mathrm{pA}$ to $250 \mathrm{pA})$, compared with WT mice $(p=0.0006$, ANOVA; Figure 2E). In response to $200 \mathrm{pA}$ current injection (100 ms), the number of spikes was significantly greater in $B D N F^{+/-}$ mice $(9.4 \pm 13.04$ APs, $n=61$ cells) than WT mice (1.76 \pm 1.11 APs, $n=41$ cells, $p<0.0001$, Welch's $t$-test), indicating increased excitability in $B D N F^{+/-}$neurons. Rheobase currents were significantly smaller in $B D N F^{+/-}$mice $(94.62 \pm 36.58 \mathrm{pA})$ than WT mice $(114.6 \pm 34 \mathrm{pA}, p=0.006$, Student's $t$-test; Figure $2 \mathrm{~F}$ ). The results indicate that reduced BDNF increases the excitability of MNTB neurons regardless of their location.

\section{At Pre-hearing Age, Reduction of BDNF Does Not Impact Tonotopic Segregation of AIS Structure in the MNTB}

BDNF reduction altered structural and physiological development of MNTB neurons that might be dependent on sound-evoked activity after hearing onset at P12. It is possible that BDNF reduction impacts intrinsic properties of MNTB neurons before hearing onset when the auditory processing is dependent on the spontaneous cochlear activity instead of soundevoked activity. Thus, to test whether a physiological level of BDNF is critical for intrinsic development, which is independent 
TABLE 1 | Summary of intrinsic properties of MNTB neurons.

\begin{tabular}{|c|c|c|c|c|}
\hline $\begin{array}{l}\text { Values represented as } \\
\text { Mean } \pm \text { SD }\end{array}$ & WT Medial & WT Lateral & $\mathrm{BDNF}^{+/-}$Medial & $\mathrm{BDNF}^{+/-}$Lateral \\
\hline Rheobase (pA) & $112 \pm 36.66^{A} n=19$ & $108.4 \pm 32.83^{A} n=15$ & $92.86 \pm 37.07^{\mathrm{A}} n=28$ & $93.42 \pm 37.07^{A} n=38$ \\
\hline Input Resistance (M $\Omega$ ) & $338 \pm 128.7^{\mathrm{A}} n=27$ & $301 \pm 84.74^{\mathrm{A}} n=17$ & $302.6 \pm 84.74^{\mathrm{A}} n=28$ & $284 \pm 123^{A} n=36$ \\
\hline AP Threshold (mV) & $-48.98 \pm 5.53^{\mathrm{A}} n=25$ & $-43 \pm 3.06^{\mathrm{B}} n=18$ & $-48.87 \pm 3.68^{\mathrm{AB}} n=26$ & $-47.38 \pm 3.68^{\mathrm{A}} n=36$ \\
\hline AP Amplitude (pA) & $73.53 \pm 10.22^{\mathrm{A}} n=25$ & $72.55 \pm 4.69^{A} n=18$ & $75 \pm 9.37^{A} n=26$ & $74.4 \pm 7.92^{\mathrm{A}} n=35$ \\
\hline AP Half-width (s) & $0.57 \pm 0.13^{\mathrm{A}} n=18$ & $0.52 \pm 0.06^{\mathrm{A}} n=15$ & $0.56 \pm 0.12^{\mathrm{A}} n=16$ & $0.56 \pm 0.17^{\mathrm{A}} n=20$ \\
\hline
\end{tabular}

Within rows, means with superscripts containing the same letter are not significantly different. Within the same row, all values with an "A" superscript are not statistically different from each other, and all values with "B" superscript are not statistically different from each other. Within a row, means superscripted with "A" are statistically different from means superscripted with " $B$ ".

of sound input, we examined the structural properties of the AIS between pre-hearing $B D N F^{+/-}$and WT mice at P9. Pre-hearing WT mice show no tonotopic segregation of AIS properties between medial and lateral neurons (Figures 3A,B), supporting the previous finding that the tonotopic refinement of AIS structures occurs in an activity-dependent manner after hearing onset. However, $B D N F^{+/-}$neurons showed a tonotopic differentiation of AIS length without difference in AIS distance from the soma between medial and lateral neurons. In $B D N F^{+/-}$ mice at P9, AIS length was shorter in medial neurons than lateral neurons $(17.71 \pm 3.39 \mu \mathrm{m}$ vs. $20.03 \pm 4.61 \mu \mathrm{m}, p=0.004$, Welch's two-tailed $t$-test). There was no difference in AIS location along the tonotopic axis $(5.29 \pm 4.15 \mu \mathrm{m}, n=37$ medial vs. $6.48 \pm 4.01 \mu \mathrm{m}, n=32$ lateral neurons, $p=0.23$, Student's $t$-test; Figure 3B).

Next, we examined whether the tonotopic differentiation in the intrinsic properties of MNTB neurons is present in $\mathrm{WT}$ and $\mathrm{BDNF}^{+/-}$mice at pre-hearing age (Figure $3 \mathrm{C}$ ). In the whole-cell recording, membrane capacitance did not differ between genotypes in the same position along the tonotopic axis at P9 (Figure 3D). At P9 before hearing onset, the AP threshold was not tonotopically different in WT neurons. However, in $B D N F^{+/-}$, lateral neurons showed a higher threshold than medial neurons (Figure 3E). AP threshold was not tonotopically organized in WT mice $(p=0.87)$, but $B D N F^{+/-}$neurons have a tonotopic difference of AP threshold $(p=0.01$, Welch's two-tailed $t$-test). Similar to WT, there was no significant difference in AP amplitude between lateral and medial neurons in $B D N F^{+/-}$mice (lateral: $68.97 \pm 6.69 \mathrm{mV}$ and medial: $70.53 \pm 5.75 \mathrm{mV}, p=0.52$, Student's $t$-test). There was no significant difference in AP amplitude between lateral and medial neurons in WT mice (lateral: $68.25 \pm 12 \mathrm{mV}$ and medial: $68.98 \pm 5.85 \mathrm{mV}, p=0.87$, Welch's test). $B D N F^{+/-}$ and WT neurons had similar input resistance within the same tonotopic location paralleling the $\mathrm{P} 21$ results (Figure 3E). Taken together, MNTB neurons from pre-hearing $B D N F^{+/-}$ mice showed tonotopic differences in AIS length and AP threshold. As opposed to unlike in WT mice. However, this tonotopic differentiation did not persist through postnatal development and disappeared after hearing onset (at P21). It suggests that BDNF level may contribute to setting intrinsic properties of MNTB neurons before hearing onset when spontaneous cochlear activity is dominant in the immature auditory system.

\section{BDNF Is Necessary for Enhanced Tonotopic Refinement Induced by the Sound Augmented Environment}

After hearing onset, sound deprivation and enhancement modify structural properties of MNTB neurons during development, and specifically, sound stimulation enhances the tonotopic differences of AIS structure (Kim et al., 2019). We hypothesized that sound stimulation increases BDNF expression which enhances the structural and physiological plasticity of MNTB neurons. Sound stimulation has been shown to increase BDNF transcript and protein levels in the brainstem (Wang et al., 2011; Matt et al., 2018). In WT mice, sound stimulation $(80 \mathrm{~dB}, 16 \mathrm{kHz}$, $3 \mathrm{~h}$ /day) from P13 to P19 increased mature BDNF protein by $25 \%$, but not pro-BDNF, in the auditory brainstem (mature BDNF: $p=0.02$, Welch's $t$-test, $n=3$ per group; pro-BDNF: $p=0.40$, Welch's $t$-test, $n=4$ /group; Figure 4A). We examined whether increased endogenous BDNF by sound stimulation rescues the lack of tonotopic differentiation of AIS structure in $B D N F^{+/-}$mice. In $B D N F^{+/-}$mice, which were exposed to the additional sound stimulation (subsequently named $B D N F^{+/-}+$ Sound mice), AIS distance from the soma was $6.51 \pm 2.21 \mu \mathrm{m}$ in medial and $6.8 \pm 2.20 \mu \mathrm{m}$ in lateral neurons $(n=36$ and 34 cells respectively, $p=0.58$, Student's $t$-test; Figures $4 \mathrm{~B}, \mathrm{C}$ ). AIS length of medial neurons was $15.72 \pm 2.24 \mu \mathrm{m}$ and the length of lateral neurons was $15.58 \pm 2.15 \mu \mathrm{m}$. AIS length did not differ along the tonotopic axis in $\mathrm{BDNF}^{+/-}+$Sound mice ( $n=35$ and 33 cells respectively, $p=0.79$, Mann-Whitney $\mathrm{U}$ test; Figure 4C). The tonotopic difference in soma size was not observed in $\mathrm{BDNF}^{+/-}+$Sound mice (Figure 4C). The result demonstrated that augmented sound inputs could not rescue the alterations in AIS structural properties of MNTB neurons caused by global $\mathrm{BDNF}$ reduction in $B D N F^{+/-}$mice.

Next, we examined the physiological properties of MNTB neurons in $\mathrm{BDNF}^{+/-}$mice following sound stimulation. Phasic plotting the $\mathrm{dV} / \mathrm{dt}$ of APs from MNTB neurons demonstrated no difference in AP threshold or amplitude between medial and lateral neurons in $\mathrm{BDNF}^{+/-}+$Sound (Figures 4D,E). Increased sound input did not induce tonotopic differentiation 
of neuronal properties in $B D N F^{+/-}$mice. Although exposed to sound stimulation, lack of tonotopic differentiation of AP threshold was maintained in $B D N F^{+/-}+$Sound mice (medial: $-45.37 \pm 5.75 \mathrm{mV}$ and lateral: $-43.98 \pm 3.62 \mathrm{mV}, p=0.47$, Student's $t$-test; Figure 4E). No significant tonotopic difference was found in AP amplitude or input resistance in $B D N F^{+/-}$ + Sound animals $(p=0.67$, Student's $t$-test; Figure $4 \mathrm{E}$ ) like $B D N F^{+/-}$animals. $B D N F^{+/-}$mice were unable to establish MNTB tonotopic gradients of intrinsic or structural properties even when exposed to an augmented sound input during the critical period of development. Mice with BDNF reduction were unable to properly respond to changes in sound-evoked activity, indicating that BDNF is a key molecule for activity-dependent structural and physiological plasticity of auditory brainstem neurons.

\section{BDNF+/- Mice Lack Frequency-Responsiveness of Neurons and Show an Impaired Tonotopy in the MNTB}

Tonotopy describes a topographic organization of frequencyresponsiveness of neurons within each auditory nucleus. To examine if BDNF reduction and associated structural and physiological alterations affect the tonotopy of MNTB neurons, we assessed neuronal activity of MNTB neurons in response to a high frequency tone sound $(16 \mathrm{kHz}, 90 \mathrm{~min}, 80 \mathrm{~dB})$ using $c$ fos, an early response gene, immunostaining (Karmakar et al., 2017; Kim et al., 2019; Figure 5A). The expression of c-Fos in the MNTB in response to $16 \mathrm{kHz}$ tone was different between $\mathrm{WT}$ and $B D N F^{+/-}$mice. In WT mice, c-Fos positive neurons $\left(\mathrm{c}-\mathrm{Fos}^{+}\right.$and $\mathrm{MAP}^{+}$) were mostly located in the medial MNTB, forming a clear band of $16 \mathrm{kHz}$ sound-sensitive neurons, in concordance with high frequency responding neurons residing in the medial portion of the MNTB (Kandler et al., 2009). However, in $\mathrm{BDNF}^{+/-}$mice, $\mathrm{c}-\mathrm{Fos}^{+}$cells were widely spread out across the MNTB without a distinct band-like expression (Figures 5B,C). The distribution analysis for $\mathrm{c}-\mathrm{Fos}^{+}$neurons along the tonotopic axis showed the expression of c-Fos in response to $16 \mathrm{kHz}$ sound was specifically concentrated on the medial MNTB from WT mice, but not in $B D N F^{+/-}$mice: $0 \%$ indicating most medial MNTB position and 100\% indicating most lateral MNTB position (WT: $32.36 \%$ and $B D N F^{+/-}$: 50.21\%; $p<0.0001$, Mann-Whitney U test; Figure 5D). The MNTB from $B D N F^{+/-}$ mice lack frequency-responsiveness of neurons to $16 \mathrm{kHz}$ sound stimulation, indicating an impaired tonotopy of the MNTB within the auditory brainstem.

To examine neuronal activation in response to $16 \mathrm{kHz}$ sound, we quantified the percentage of $\mathrm{c}-F o s^{+}$neurons (c-Fos ${ }^{+}$and $\mathrm{MAP}^{+}$cell \#/MAP2 ${ }^{+}$cell \# $\left.{ }^{\star} 100\right)$ within the MNTB between genotypes. In response to $16 \mathrm{kHz}$ tone, the percentage of c$\mathrm{Fos}^{+}$cells was significantly higher in $\mathrm{BDNF}^{+/-}$mice compared to WT ( $n=5$ and 3 , respectively; $p=0.018$, Welch's $t$-test; Figure 5E), indicating that more MNTB neurons were responsive to the $16 \mathrm{kHz}$ tone sound regardless of their location. The result paralleled physiological properties showing an increased excitability of MNTB neurons in $\mathrm{BDNF}^{+/-}$mice (Figure 2E).
Taken together, $B D N F^{+/-}$mice had hyperexcitable MNTB neurons and disorganized isofrequency bands based on the spatial organization of neural activity in response to high frequency sound.

\section{DISCUSSION}

The results demonstrated the role of BDNF in the structural and physiological refinement of MNTB neurons along the mediolateral tonotopic axis using a $B D N F^{+/-}$mouse. Our study is the first ex vivo investigation of AIS plasticity with a global reduction of $\mathrm{BDNF}$, which allows us to maintain circuit connections within a sensory system dependent on peripheral inputs. Tonotopy, a driving organization principle of the auditory system, relies on not only sound input but also BDNF signaling to establish proper gradients within the auditory brainstem and ensure precise binaural processing.

\section{Role of BDNF in the Structural Development of the MNTB}

BDNF is an important neurotrophic factor for neural development in an activity-dependent manner, whether that is driven by peripheral inputs or spontaneous activity (Kuczewski et al., 2008; Jiao et al., 2011). We addressed the impact of global $\mathrm{BDNF}$ reduction on the structural and physiological refinement of the AIS in a sound input-dependent manner in mature MNTB neurons (at P20) and in a sound input-independent manner in immature neurons in the pre-hearing stage (at P9). Previous works show that tonotopic gradients of $\mathrm{K}_{V}$ channel expression and currents require sound input since pre-hearing and congenitally deaf animals do not possess these gradients (von Hehn et al., 2004; Leao et al., 2006; Kim et al., 2019). BDNF is a molecular mediator of neural activity-dependent plasticity shown in LTP of the hippocampus CA1 synapse (Korte et al., 1995; Patterson et al., 1996) and the visual cortex (Akaneya et al., 1997; Huber et al., 1998), as well as structural plasticity of myelin following increased sound input in humans and rats (Bengtsson et al., 2005; de Villers-Sidani et al., 2010). Within the auditory system, BDNF expression is dependent on sound-evoked activity shown with increased BDNF transcript and protein levels in the brainstem following sound stimulation (Wang et al., 2011; Matt et al., 2018). Here we found that at a pre-hearing age when peripheral sound input is not involved in recruiting BDNF, a global reduction of BDNF alters the AIS location of MNTB neurons and abnormally promotes tonotopic differences of AIS length and AP threshold. As opposite to WT mice, tonotopic gradients are present at $\mathrm{P} 9$ in $B D N F^{+/-}$that are completely abolished by $\mathrm{P} 21$. BDNF reduction appears to have disparate effects on tonotopic refinement pre-hearing compared to post-hearing onset, although the underlying mechanism of the disparate effects is not understood. It is known that spontaneous activity driven by supporting cells in the cochlea occurs before hearing onset and allows for intrinsic sound-independent activity throughout the auditory pathway (Sonntag et al., 2009; Babola et al., 2018). Detectable levels of BDNF are present in the brainstem by $\mathrm{P} 6$, and spontaneous firing from brainstem neurons drives activity-dependent expression of BDNF before 
hearing onset (Hafidi, 1999). Thus, the differences were seen in AIS structure between WT and $B D N F^{+/-}$mice before hearing onset could be due to the discrepancy of spontaneous activity between genotypes. BDNF effects on spontaneous activity in pre-hearing age and sound-evoked activity in post-hearing age might be different during development. In the condition with reduced $\mathrm{BDNF}$, spontaneous activity may play a compensatory role in setting intrinsic properties of MNTB neurons, but when switching from spontaneous to sound-evoked activity after hearing onset, this compensatory effect may disappear. It would be worthy to test this hypothesis in future studies.

\section{BDNF Modulates the Neuronal Activity of MNTB Neurons}

The effects of BDNF on neuronal excitability are variable and there are different acute vs. chronic effects. In $B D N F^{+/-}$mice, chronically reduced BDNF levels decreased neuronal activity of pyramidal neurons in the entorhinal cortex (Abidin et al., 2019). We found that regardless of tonotopic location, MNTB neurons from $B D N F^{+/-}$mice showed a hyperexcitability in response to depolarizing current injection and increased neuronal activity in response to high frequency tone exposure compared to WT littermates. Interestingly, an overall increase of neuronal activity was observed, but the tonotopy of the auditory brainstem has been impaired in $B D N F^{+/-}$mice. In vitro administration of BDNF increased cell excitability in cultured hippocampal and sensory neurons (Zhang et al., 2008; Guo et al., 2017), but bath perfusion of BDNF reduced excitability of interneurons in the dentate gyrus (Holm et al., 2009; Nieto-Gonzalez and Jensen, 2013). The variable response to BDNF administration might be due to varied ion channel expression, which is influenced by BDNF signaling, across different brain regions.

\section{Physiological Relevance}

How does the disruption of the tonotopic arrangement of neuronal properties impact auditory function? Several genetically modified mice lacking tonotopic gradients of neuronal structure display auditory function abnormalities. CXCR1 mutant mice, which have disrupted microglia-neuron communication, lacked the soma size tonotopic gradient observed in WT mice and had longer peak latencies of the auditory brainstem responses (ABRs) with the normal threshold of ABRs (Milinkeviciute et al., 2021). Ephrin-A3 mutants, which lack a key axon guidance signaling factor, have degraded frequency-responsiveness tonotopy within the cochlear nucleus. These mice have deficits in signal

\section{REFERENCES}

Abidin, İ., Aydin-Abidin, S., and Mittmann, T. (2019). Neuronal excitability and spontaneous synaptic transmission in the entorhinal cortex of BDNF heterozygous mice. Neurosci. Lett. 690, 69-75. doi: 10.1016/j.neulet.2018. 10.019

Akaneya, Y., Tsumoto, T., Kinoshita, S., and Hatanaka, H. (1997). Brain-derived neurotrophic factor enhances long-term potentiation in rat visual cortex. J. Neurosci. 17, 6707-6716. doi: 10.1523/JNEUROSCI.17-17-06707.1997

Akter, N., Adachi, R., Kato, A., Fukaya, R., and Kuba, H. (2018). Auditory input shapes tonotopic differentiation of Kv1.1 expression in avian cochlear nucleus during late development. J. Neurosci. 38, 2967-2980. doi: 10.1523/JNEUROSCI. 2472-17.2018 conduction and frequency discrimination with a normal hearing threshold (Hoshino et al., 2021). Outside of genetic modifications, aging disrupts precise tonotopic organization from the cochlear nucleus to the auditory cortex as hearing function degrades (Caspary et al., 2005; de Villers-Sidani et al., 2010). It appears that sound input is required to establish and maintain tonotopy, which is required to maintain proper auditory processing. Thus, it is worthy to further examine whether $B D N F^{+/-}$mice lacking tonotopy of $\mathrm{MNTB}$ neurons along the mediolateral axis have auditory processing deficits.

\section{DATA AVAILABILITY STATEMENT}

The raw data supporting the conclusions of this article will be made available by the authors, without undue reservation.

\section{ETHICS STATEMENT}

The animal study was reviewed and approved by the UT Health San Antonio Institutional Animal Care and Use Committee.

\section{AUTHOR CONTRIBUTIONS}

MW and JK contributed to the conception and design of the study. MW collected and analyzed the data. All authors contributed to the article and approved the submitted version.

\section{FUNDING}

This work was supported by a grant from the National Institute on Deafness and Other Communication Disorders (NIDCD; R01 DC018797) to JK and a pre-doctoral grant from the Biology of Aging Department at UT Health San Antonio (T32AG021890-18) to MW.

\section{ACKNOWLEDGMENTS}

We would like to thank Dr. Manzoor Bhat for providing the $\beta 4$ spectrin primary antibody. We also thank Drs. Eun Jung Kim and Elizabeth Gould for providing technical assistance. Confocal images were generated in the Core Optical Imaging Facility, which is supported by UT Health San Antonio and NIH-NCI P30 CA54174.

Anomal, R., de Villers-Sidani, E., Merzenich, M. M., and Panizzutti, R. (2013) Manipulation of BDNF signaling modifies the experience-dependent plasticity induced by pure tone exposure during the critical period in the primary auditory cortex. PLoS One 8:e64208. doi: 10.1371/journal.pone.0064208

Babola, T. A., Li, S., Gribizis, A., Lee, B. J., Issa, J. B., Wang, H. C., et al. (2018). Homeostatic control of spontaneous activity in the developing auditory system. Neuron 99, 511-524.e5. doi: 10.1016/j.neuron.2018.07.004

Bengtsson, S. L., Nagy, Z., Skare, S., Forsman, L., Forssberg, H., and Ullén, F. (2005). Extensive piano practicing has regionally specific effects on white matter development. Nat. Neurosci. 8, 1148-1150. doi: 10.1038/ nn1516

Caspary, D. M., Schatteman, T. A., and Hughes, L. F. (2005). Age-related changes in the inhibitory response properties of dorsal cochlear nucleus 
output neurons: role of inhibitory inputs. J. Neurosci. 25, 10952-10959. doi: 10.1523/JNEUROSCI.2451-05.2005

de Villers-Sidani, E., Alzghoul, L., Zhou, X., Simpson, K. L., Lin, R. C., and Merzenich, M. M. (2010). Recovery of functional and structural age-related changes in the rat primary auditory cortex with operant training. Proc. Natl. Acad. Sci. U S A 107, 13900-13905. doi: 10.1073/pnas.1007885107

Grubb, M. S., and Burrone, J. (2010). Activity-dependent relocation of the axon initial segment fine-tunes neuronal excitability. Nature 465, 1070-1074. doi: 10.1038 /nature 09160

Guo, Y., Su, Z. J., Chen, Y. K., and Chai, Z. (2017). Brain-derived neurotrophic factor/neurotrophin 3 regulate axon initial segment location and affect neuronal excitability in cultured hippocampal neurons. J. Neurochem. 142, 260-271. doi: 10.1111/jnc. 14050

Hafidi, A. (1999). Distribution of BDNF, NT-3 and NT-4 in the developing auditory brainstem. Int. J. Dev. Neurosci. 17, 285-294. doi: 10.1016/s07365748(99)00043-x

Holm, M. M., Nieto-Gonzalez, J. L., Vardya, I., Vaegter, C. B., Nykjaer, A., and Jensen, K. (2009). Mature BDNF, but not proBDNF, reduces excitability of fast-spiking interneurons in mouse dentate gyrus. J. Neurosci. 29, 12412-12418. doi: 10.1523/JNEUROSCI.2978-09.2009

Hoshino, N., Altarshan, Y., Alzein, A., Fernando, A. M., Nguyen, H. T., Majewski, E. F., et al. (2021). Ephrin-A3 is required for tonotopic map precision and auditory functions in the mouse auditory brainstem. J. Comp. Neurol. 529, 3633-3654. doi: 10.1002/cne.25213

Huber, K. M., Sawtell, N. B., and Bear, M. F. (1998). Brain-derived neurotrophic factor alters the synaptic modification threshold in visual cortex. Neuropharmacology 37, 571-579. doi: 10.1016/s0028-3908(98)00050-1

Jiao, Y., Zhang, Z., Zhang, C., Wang, X., Sakata, K., Lu, B., et al. (2011). A key mechanism underlying sensory experience-dependent maturation of neocortical GABAergic circuits in vivo. Proc. Natl. Acad. Sci. U S A 108, 12131-12136. doi: 10.1073/pnas.1105296108

Kandler, K., Clause, A., and Noh, J. (2009). Tonotopic reorganization of developing auditory brainstem circuits. Nat. Neurosci. 12, 711-717. doi: $10.1038 / \mathrm{nn} .2332$

Karmakar, K., Narita, Y., Fadok, J., Ducret, S., Loche, A., Kitazawa, T., et al. (2017). Hox 2 genes are required for tonotopic map precision and sound discrimination in the mouse auditory brainstem. Cell Rep. 18, 185-197. doi: 10.1016/j.celrep. 2016.12.021

Kim, E. J., Feng, C., Santamaria, F., and Kim, J. H. (2019). Impact of auditory experience on the structural plasticity of the AIS in the mouse brainstem throughout the lifespan. Front. Cell. Neurosci. 13:456. doi: 10.3389/fncel.2019. 00456

Korte, M., Carroll, P., Wolf, E., Brem, G., Thoenen, H., and Bonhoeffer, T. (1995). Hippocampal long-term potentiation is impaired in mice lacking brainderived neurotrophic factor. Proc. Natl. Acad. Sci. U S A 92, 8856-8860. doi: $10.1073 /$ pnas.92.19.8856

Kuba, H., Oichi, Y., and Ohmori, H. (2010). Presynaptic activity regulates $\mathrm{Na}(+)$ channel distribution at the axon initial segment. Nature 465, 1075-1078. doi: 10.1038 /nature 09087

Kuba, H., Adachi, R., and Ohmori, H. (2014). Activity-dependent and activityindependent development of the axon initial segment. J. Neurosci. 34, 3443-3453. doi: 10.1523/JNEUROSCI.4357-13.2014

Kuba, H., Ishii, T., and Ohmori, H. (2006). Axonal site of spike initiation enhances auditory coincidence detection. Nature 444, 1069-1072. doi: 10.1038/nature05347

Kuczewski, N., Langlois, A., Fiorentino, H., Bonnet, S., Marissal, T., Diabira, D., et al. (2008). Spontaneous glutamatergic activity induces a BDNF-dependent potentiation of GABAergic synapses in the newborn rat hippocampus. J. Physiol. 586, 5119-5128. doi: 10.1113/jphysiol.2008.158550

Leao, R. N., Sun, H., Svahn, K., Berntson, A., Youssoufian, M., Paolini, A. G., et al. (2006). Topographic organization in the auditory brainstem of juvenile mice is disrupted in congenital deafness. J. Physiol. 571, 563-578. doi: 10.1113/jphysiol. 2005.098780

Li, W., Kaczmarek, L. K., and Perney, T. M. (2001)., Localization of two high-threshold potassium channel subunits in the rat central auditory system. J. Comp. Neurol. 437, 196-218. doi: 10.1002/cne.1279
Matt, L., Eckert, P., Panford-Walsh, R., Geisler, H. S., Bausch, A. E., Manthey, M., et al. (2018). Visualizing BDNF transcript usage during sound-induced memory linked plasticity. Front. Mol. Neurosci. 11:260. doi: 10.3389/fnmol. 2018.00260

Milinkeviciute, G., Chokr, S. M., Castro, E. M., and Cramer, K. S. (2021). CX3CR1 mutation alters synaptic and astrocytic protein expression, topographic gradients and response latencies in the auditory brainstem. J. Comp. Neurol. 529, 3076-3097. doi: 10.1002/cne.25150

Nieto-Gonzalez, J. L., and Jensen, K. (2013). BDNF depresses excitability of parvalbumin-positive interneurons through an M-like current in rat dentate gyrus. PLoS One 8:e67318. doi: 10.1371/journal.pone.0067318

Parameshwaran, S., Carr, C. E., and Perney, T. M. (2001). Expression of the Kv3.1 potassium channel in the avian auditory brainstem. J. Neurosci. 21, 485-494. doi: 10.1523/JNEUROSCI.21-02-00485.2001

Patterson, S. L., Abel, T., Deuel, T. A., Martin, K. C., Rose, J. C., and Kandel, E. R. (1996). Recombinant BDNF rescues deficits in basal synaptic transmission and hippocampal LTP in BDNF knockout mice. Neuron 16, 1137-1145. doi: 10.1016/s0896-6273(00)80140-3

Schimmang, T., Tan, J., Müller, M., Zimmermann, U., Rohbock, K., Kôpschall, I., et al. (2003). Lack of Bdnf and TrkB signalling in the postnatal cochlea leads to a spatial reshaping of innervation along the tonotopic axis and hearing loss. Development 130, 4741-4750. doi: 10.1242/dev.00676

Sonntag, M., Englitz, B., Kopp-Scheinpflug, C., and Rübsamen, R. (2009). Early postnatal development of spontaneous and acoustically evoked discharge activity of principal cells of the medial nucleus of the trapezoid body: an in vivo study in mice. J. Neurosci. 29, 9510-9520. doi: 10.1523/JNEUROSCI.1377-09. 2009

von Hehn, C. A., Bhattacharjee, A., and Kaczmarek, L. K. (2004). Loss of Kv3.1 tonotopicity and alterations in cAMP response element-binding protein signaling in central auditory neurons of hearing impaired mice. J. Neurosci. 24, 1936-1940. doi: 10.1523/JNEUROSCI.4554-03.2004

Wang, H., Brozoski, T. J., Ling, L., Hughes, L. F., and Caspary, D. M. (2011). Impact of sound exposure and aging on brain-derived neurotrophic factor and tyrosine kinase $\mathrm{B}$ receptors levels in dorsal cochlear nucleus 80 days following sound exposure. Neuroscience 172, 453-459. doi: 10.1016/j.neuroscience.2010. 10.056

Weatherstone, J. H., Kopp-Scheinpflug, C., Pilati, N., Wang, Y., Forsythe, I. D., Rubel, E. W., et al. (2017). Maintenance of neuronal size gradient in MNTB requires sound-evoked activity. J. Neurophysiol. 117, 756-766. doi: 10.1152/jn. 00528.2016

Wiechers, B., Gestwa, G., Mack, A., Carroll, P., Zenner, H. P., and Knipper, M. (1999). A changing pattern of brain-derived neurotrophic factor expression correlates with the rearrangement of fibers during cochlear development of rats and mice. J. Neurosci. 19, 3033-3042. doi: 10.1523/JNEUROSCI.19-08-03033. 1999

Zhang, Y. H., Chi, X. X., and Nicol, G. D. (2008). Brain-derived neurotrophic factor enhances the excitability of rat sensory neurons through activation of the 75 neurotrophin receptor and the sphingomyelin pathway. J. physiol. 586, 3113-3127. doi: 10.1113/jphysiol.2008.152439

Conflict of Interest: The authors declare that the research was conducted in the absence of any commercial or financial relationships that could be construed as a potential conflict of interest.

Publisher's Note: All claims expressed in this article are solely those of the authors and do not necessarily represent those of their affiliated organizations, or those of the publisher, the editors and the reviewers. Any product that may be evaluated in this article, or claim that may be made by its manufacturer, is not guaranteed or endorsed by the publisher.

Copyright (๑) 2022 Wollet and Kim. This is an open-access article distributed under the terms of the Creative Commons Attribution License (CC BY). The use, distribution or reproduction in other forums is permitted, provided the original author(s) and the copyright owner(s) are credited and that the original publication in this journal is cited, in accordance with accepted academic practice. No use, distribution or reproduction is permitted which does not comply with these terms. 